\title{
«HAN TAL BEC VOSTRES GALLINES?» SOBRE LA REPRESENTACIÓN MEDIEVAL DEL FALO A TRAVÉS DE ALGUNOS EJEMPLOS ICONOGRÁFICOS Y LITERARIOS PERTENECIENTES A LA NARRATIVA CATALANA DEL SIGLO XV
}

\author{
Jerónimo Méndez Cabrera²
}

\begin{abstract}
RESUMEN
El objetivo principal del presente trabajo, de carácter aproximativo, ha sido reunir, clasificar e interpretar algunas muestras significativas, tanto iconográficas como textuales, con el propósito de ofrecer una síntesis sobre los orígenes y modalidades de la conceptualización medieval del falo, poniendo en relación las tipologías de ciertas representaciones visuales y las drôleries de la marginalia manuscrita con lo que encontramos en algunos textos de la narrativa catalana del siglo XV, como el Llibre de fra Bernat, el Col-loqui de dames, Lo procés de les olives y Lo somni de Joan Joan, encontrando así algunas claves interpretativas para el estudio de la literatura medieval.
\end{abstract}

Palabras clave: Falo, sexualidad medieval, literatura del XV, narrativa catalana, arte románico, erotismo medieval, marginalia.

\begin{abstract}
The main aim of this article has been gathering, classifying and interpreting some meaningful iconographic and textual samples as well in order to offer a synthesis about the origins and modalities of the medieval conceptualization of the phallus, relating the typology of certain visual representations and the drôleries of the manuscript marginalia to what we can find in several texts of the Catalan narrative in the $15^{\text {th }}$ century as the Llibre de fra Bernat, el Col-loqui de dames, Lo procés de les olives and Lo somni de Joan Joan, and discovering some interpretative keys for the study of the medieval literature.
\end{abstract}

Keywords: Phallus, medieval sexuality, fifteenth-century literature, Catalan narrative, Romanesque art, medieval eroticism, marginalia.

Fecha de recepción: 30 septiembre 2009. Fecha de aceptación: 26 noviembre 2009.

1 El presente trabajo se enmarca en el proyecto de investigación La cultura literaria medieval y moderna en la tradición manuscrita e impresa (IV), referencia FII 2009-14206, financiado por el Ministerio de Ciencia e Innovación de España.

2 Universidad de Valencia. Email: jeronimo.mendez@uv.es. 


\section{OBJETIVOS Y METODOLOGÍA}

El objetivo principal del presente trabajo ha sido reunir, clasificar e interpretar un número significativo de muestras, tanto iconográficas (algunas ya conocidas) como textuales (ignoradas hasta ahora en este sentido), que dieran cuenta de la representación medieval del elemento fálico. El uso de una metodología comparativa nos ha llevado a contrastar ejemplos iconográficos y obras literarias que, en su conjunto, pertenecen a un amplio período que va al menos desde la Antigüedad tardía hasta la Baja Edad Media. Se trata, pues, de un trabajo aproximativo que pretende ofrecer una síntesis hasta ahora inédita sobre los orígenes y modalidades de la conceptualización medieval del falo. De sobras es sabido que la representación iconográfica de elementos, personajes, situaciones y posturas sexuales en clave grotesca abunda en la decoración arquitectónica de canecillos, ménsulas y capiteles románicos, así como en lugares marginales y misericordias de templos góticos. Sin embargo, hasta ahora no se ha intentado una explicación comparativa global que ponga en relación las tipologías de estas representaciones visuales y las drôleries de la marginalia manuscrita con lo que encontramos en algunos textos románicos de la Baja Edad Media, concretamente en el Llibre de fra Bernat, el Col-loqui de dames, Lo procés de les olives y Lo somni de Joan Joan.

\section{EL FALO COMO SER AUTÓNOMO: MENUDO PÁJARO}

A lo largo de los siglos medievales encontramos en diferentes lugares una peculiar iconografía en la que el falo es representado como si de un pequeño animal alado se tratase. Es el caso, por ejemplo, del canecillo que encontramos en la Iglesia de San Lorenzo de Zorita del Páramo (Palencia), en el que podemos apreciar lo que parece ser una figura fálica de prominente cabeza, alas con plumaje detallado y visibles patas de ave (fig. 1). Otra muestra representativa, alejada en este caso del arte románico, es la insignia de estaño perteneciente a un peregrino inglés del siglo XIV en forma de grueso falo alado con patas (fig 2, The British Museum, Londres) ${ }^{3}$. Para captar el significado cultural de esta forma de representación fálica como ser independiente es necesario remontarse a los antecedentes que encontramos, en este sentido, en la cultura clásica.

El ave fálica o pájaro-falo era utilizado en la antigua Grecia durante los rituales de fertilidad y en procesiones dionisíacas en las que los participantes llevaban estandartes fálicos. El culto al falo, como popular símbolo de fertilidad, relacionado con el dios Príapo y la figura hipersexual del sátiro (Lissarrague: 1990: 53), constituía un importante rito de las celebraciones en honor a Dioniso. De hecho, podemos apreciar una muestra

3 El caso es que estas insignias, normalmente para capas y sombreros, eran normalmente objetos de carácter religioso, cruces, etc. (aún hoy existen broches y medallas de vírgenes, santos, etc.) y estaban relacionados en la Europa medieval con la actividad del peregrinaje. Era cosa habitual que los peregrinos que habían viajado a ciertos emplazamientos de devoción cristiana lucieran después el símbolo representativo de ese lugar. Algunas insignias, sin embargo, eran totalmente seculares y representaban imágenes explícitamente sexuales: genitales masculinos o incluso femeninos personificados con piernas y brazos, tal vez para ridiculizar o satirizar de manera visual la falsa piedad de algunas mujeres que tomaban parte en peregrinajes con el propósito real de vivir aventuras sexuales (Johns 2004: 34). 


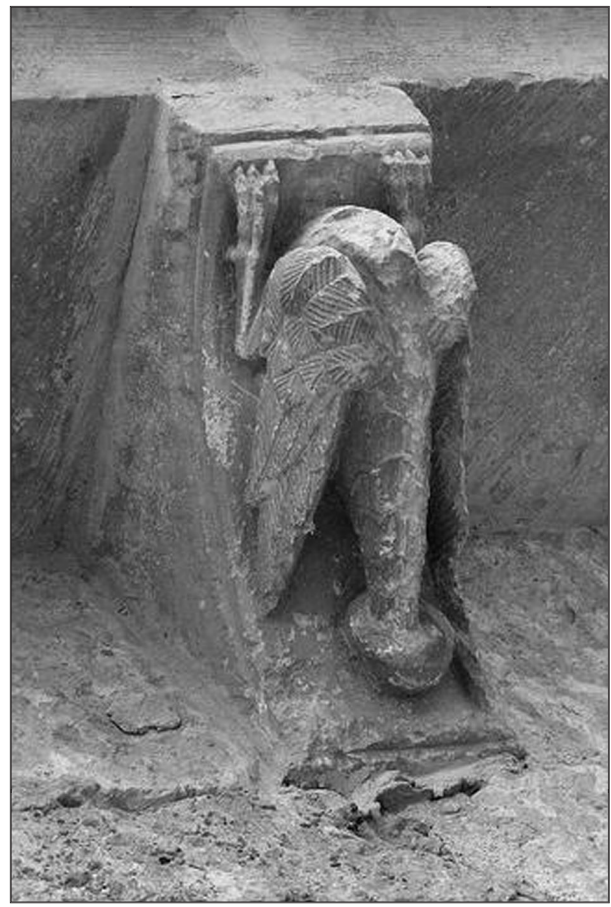

Fig. 1.

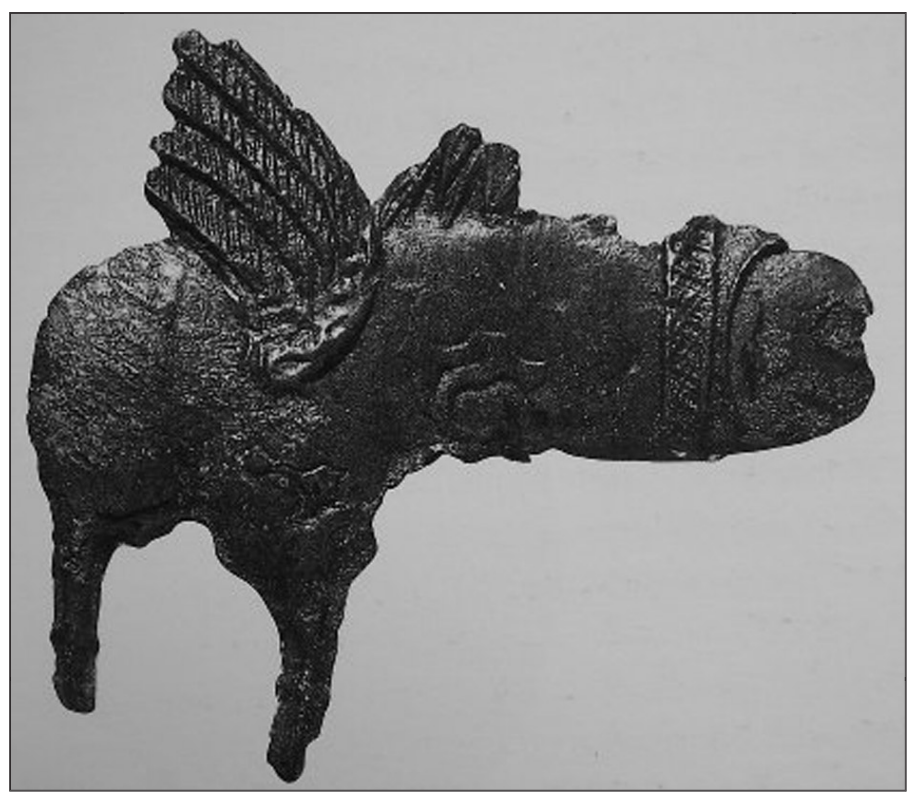

Fig. 2 . 


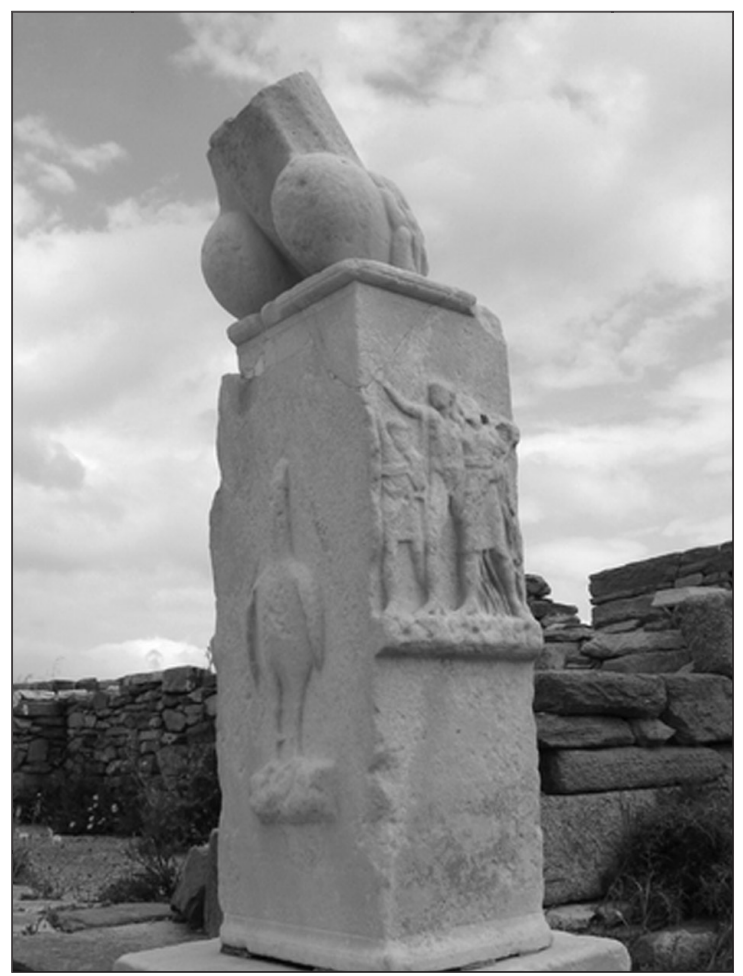

Fig. 3.

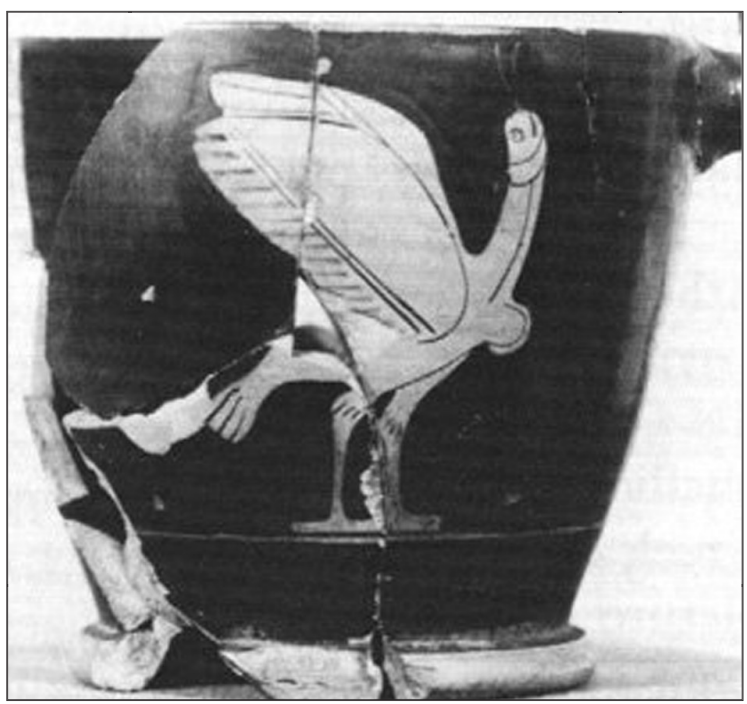

Fig. 4. 
iconográfica que relaciona ya este culto con la imagen de un pájaro en el mismo templo de Dioniso, en Delos (300 A.C.), donde podemos observar en una de las columnas que sostienen las ruinas de lo que fue un enorme falo, la figura en relieve de un ave, símbolo de la inmortalidad humana (fig. 3). Así, las imágenes fálicas en monumentos públicos y emplazamientos domésticos - e incluso comerciales - se pueden encontrar en diferentes contextos a lo largo del mundo griego, puesto que los iconos fálicos eran habitualmente emplazados en el exterior de las casas, en entradas, muros y jardines, límites, tumbas, etc. Y eran usados como símbolos de protección no sólo de lugares sino también de individuos: amuletos de bronce, latón, hueso o incluso oro en forma de falo, alado o no, eran a menudo utilizados como pendientes o colgantes por adultos y niños para proteger del mal de ojo y la mala suerte; sin olvidar que la imagen fálica aparece también en lámparas, figuras votivas, ornamentos varios, tintinnabula, en cerámica y vasijas.

Podemos encontrar ya algunos ejemplos de la imagen del falo con alas en la cerámica griega que va del 600 al 400 A.C. ${ }^{4}$ En primer lugar, se conserva una jarra ateniense donde podemos observar un ave con cabeza en forma de falo (fig. 4, Museum of Fine Arts, Boston); en un skyphos de figuras rojas una de éstas aves fálicas levanta la cabeza mirando hacia las partes traseras de un sileno (fig. 5, Boston); y es también significativa otra vasija de este tipo, en la que se puede apreciar una mujer sosteniendo uno de estos falos alados para introducirlo en un recipiente donde parece coleccionar, con algún propósito, estas curiosas criaturas (fig. 6, Petit Palais, París) 5

Por otra parte, se sabe que en la cultura romana la imagen del falo, conocida como fascinum, promovía la fortuna y espantaba la mala suerte. No era un elemento erótico en sentido estricto y estaba alejada normalmente de cualquier concepción relacionada con el disfrute sensual de manera exclusiva (Johns 2004: 27). Las representaciones fálicas eran también amuletos o iconos de la buena suerte relacionados con Príapo (representado habitualmente con un falo desproporcionado y con la abundancia de una cesta cargada de frutos), o con Mutinus Mutunus, deidad romana equivalente al dios griego ${ }^{6}$. En cuanto a la representación del pájaro fálico, podemos observar una vasija de la Bretaña romana (s. II-III D.C.) en cuya superficie se encuentra grabada la figura de un falo con alas y

4 Según Skinner (2005: 79), podemos considerar este período como la Edad de Oro de la cerámica ática. A partir del 575 hasta el 450 A.C., aproximadamente, la escenas sexuales explícitas en la decoración cerámica serán bastante populares.

5 Keuls (1993:82) identifica estas figuras como olisboi (dildos) y obvia cualquier comentario sobre el falo alado que sostiene la mujer con su brazo y sobre los pequeños ojos que presentan estos supuestos olisboi, representándose así como criaturas con vida propia. Por otra parte, realiza una observación acerca de la sexualidad femenina en la Atenas clásica que parece aplicable, salvando las distancias, a las ideas medievales sobre este tema: «How the female psyche developed in Classical Athens under this barrage of verbal and visual phallicism, we can never know, because we have no expressions of the women's sexual idiosyncrassies. If women are, indeed, subject to penys envy, those of Athens may have suffered a massive case of it, but our sources document only male ideas of female sexuality. Since Athen's society had promoted the male organ as the symbol of fertility, parentho$o d$, creativity and self-defense, it is only natural that Athenian men could not conceive of women otherwise than as obsessed with insatiable lust to fill up their vaginal void with penises, real or artifical».

6 El dios romano Liber, deidad del crecimiento y la fecundidad, heredó algunos aspectos del griego Príapo. Era representado normalmente por medio de un símbolo fálico, no sólo relacionado con el sexo sino también como desafío y protección contra el mal de ojo (Tannahill 1991: 118). 


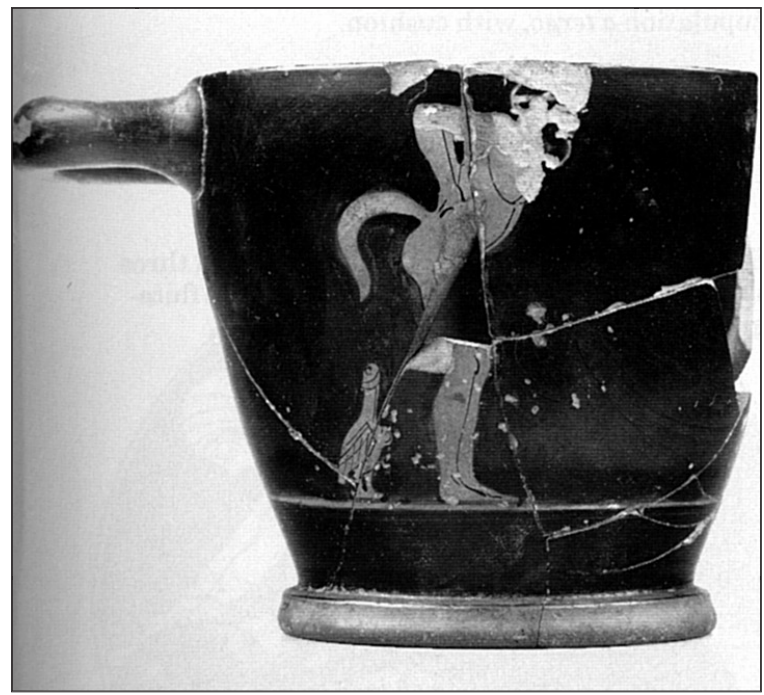

Fig. 5.

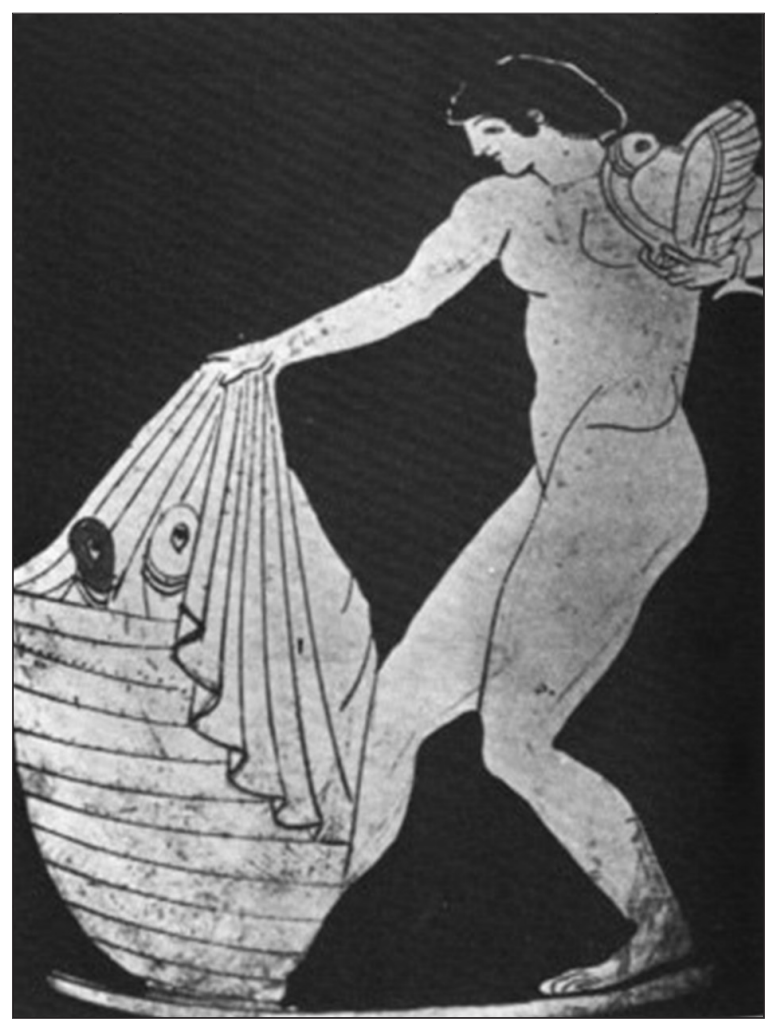

Fig. 6. 


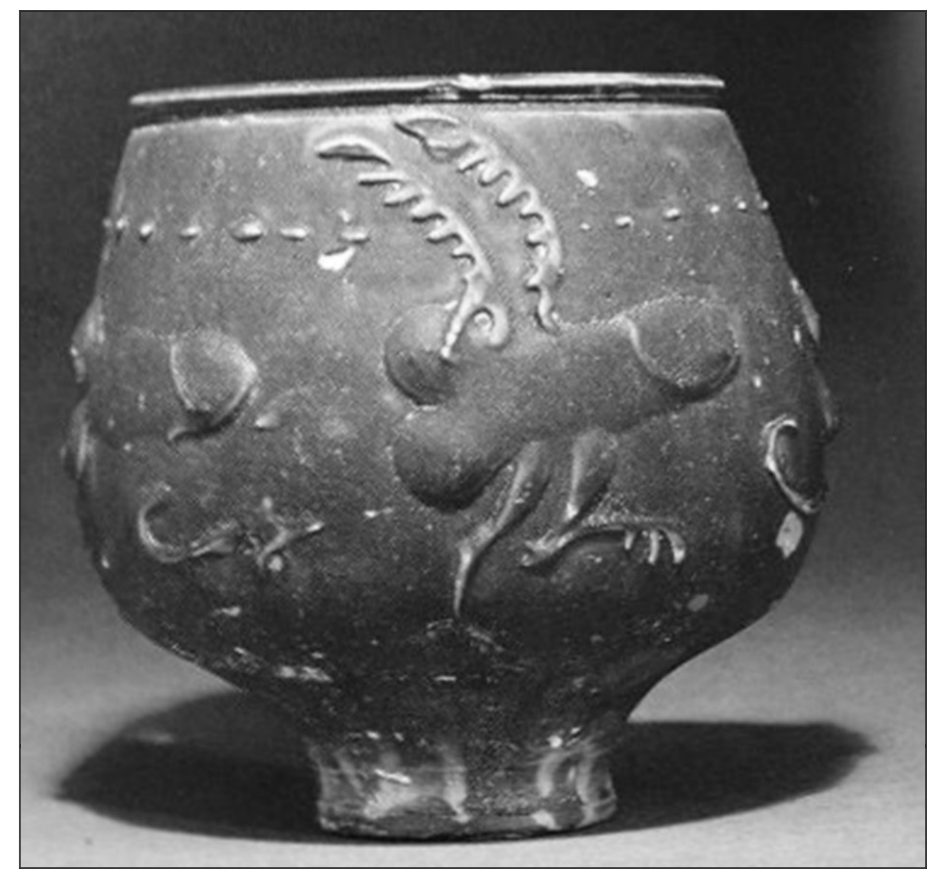

Fig. 7.

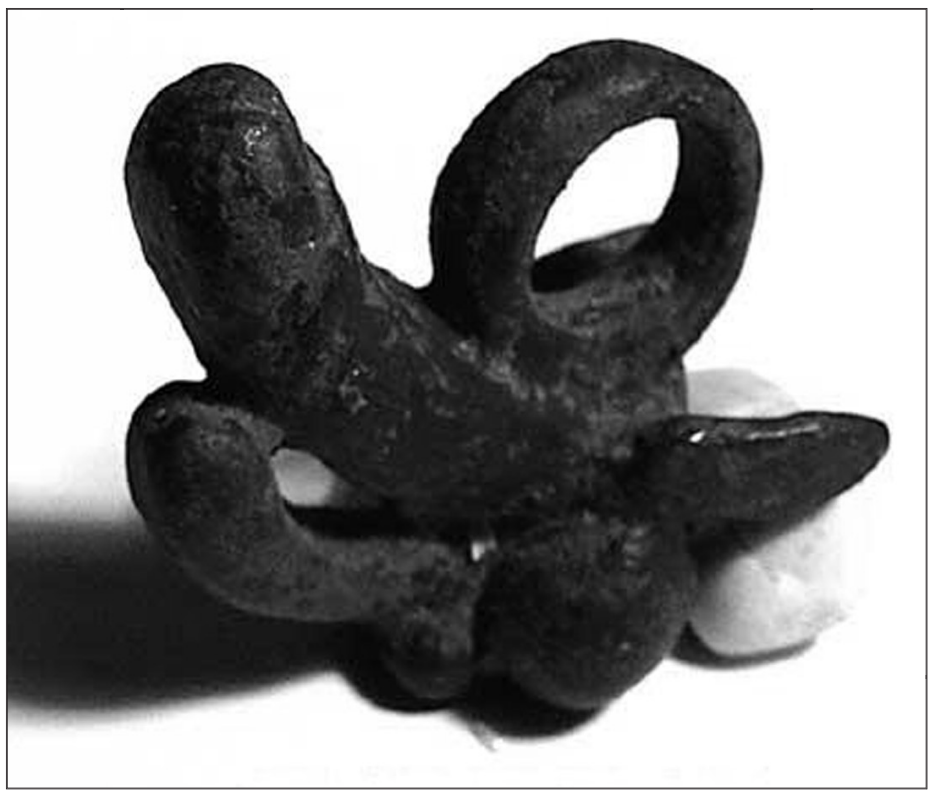

Fig. 8. 


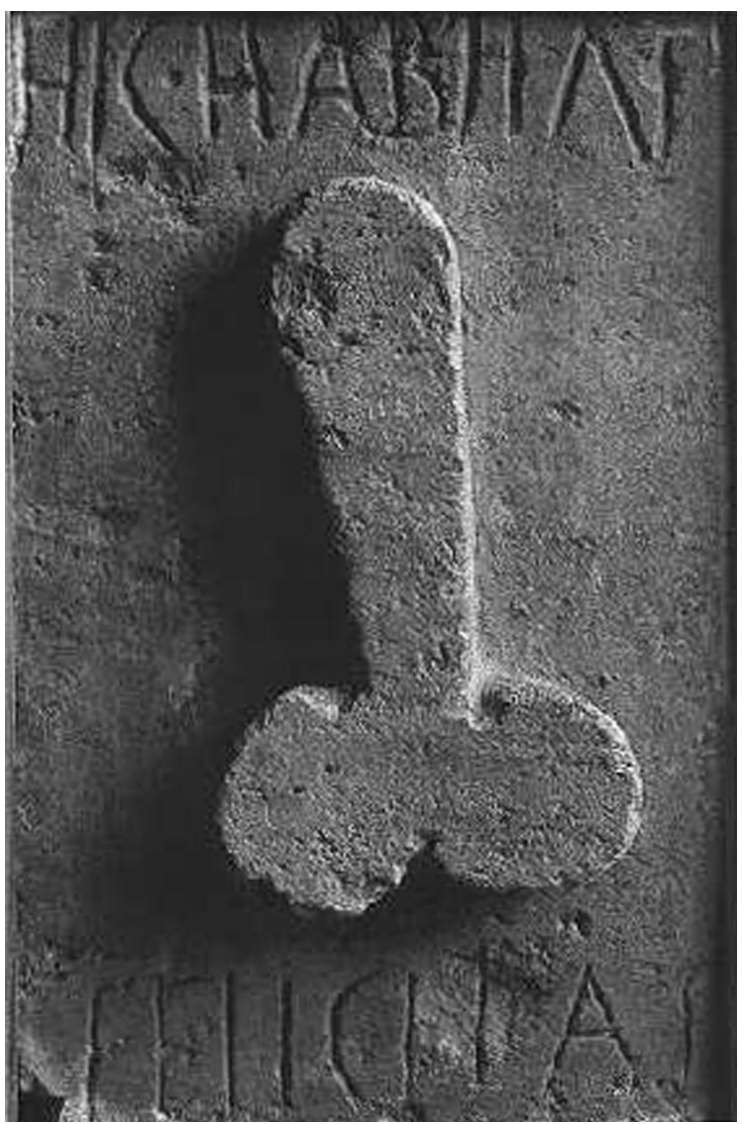

Fig. 9.

patas de ave (fig. 7, British Museum). Existen, además, numerosos amuletos de bronce conservados que presentan también la forma del falo alado (fig. 8) 7 . Y es que el simbolismo sexual, fálico por antonomasia, era protector y atraía la buena suerte. Así se puede comprobar en una placa conservada, procedente de Pompeya, que estaba situada en su origen en el muro de una casa para proteger el hogar de los malos espíritus y atraer la buena fortuna, donde se puede apreciar un gran falo con la inscripción «HIC HABITAT FELICITAS» (fig. 9) . $^{8}$

7 Esta representación fálica está relacionada, seguramente, con los términos de jerga latina para el órgano sexual masculino, que han pasado inalterables a lo largo de los siglos del latín a las lenguas románicas y han dado lugar a conocidas designaciones coloquiales del falo: polla, pardal, piu, pau, etc.

8 Grant (1975: 104) llega a afirmar en este sentido, haciendo referencia a los canecillos fálicos del arte románico: «The custom of placing the sign of the phallus on houses to avert evil spirits continued into medieval times, and examples have been found on the walls of churches». 
La pervivencia de esta imagen del falo alado en la cultura medieval es indudablemente una herencia de la cultura clásica. Sin embargo, ello no implica necesariamente la pervivencia del mismo significado o concepción de la imagen. Precisamente por eso, el hecho de encontrarnos la misma representación, el falo como ser independiente con atributos de ave, a lo largo de toda la Edad Media, nos hace pensar que, aunque la forma de la imagen resulta prácticamente la misma, su significado debe de ser distinto, puesto que el contexto cultural - y sobretodo religioso - en el que aparece lo es. Sin embargo, no tenemos los datos suficientes para aseverar que los broches o insignias, por ejemplo, no fueran todavía amuletos de la buena suerte, esta vez con connotaciones religiosas distintas. Si hacemos una suposición que tenga en cuenta algunas constantes culturales del medievo, podríamos pensar que estos objetos rallaban ya en lo tabú sexual y, por tanto, adquirían matices de humorismo o de cierto significado satírico.

Resulta útil, sin embargo, tener en cuenta esta tradición iconográfica para interpretar de manera fehaciente algún pasaje que pertenece a la literatura satírica bajomedieval y, concretamente, a la narrativa catalana del siglo XV9. En el Llibre de fra Bernat, donde el notario gironés Francesc de la Via nos narra las fechorías de un perverso fraile deseoso de una no menos traviesa malmonjada, podemos leer cómo, después de que ésta le exija algún presente en el convento a cambio de sus favores, fray Bernat, enfadado y excitado por las continuas exigencias de la joven monja, y después de observar cómo ésta coquetea con un caballero y un canónigo, le ofrece con descaro un buen regalo (Pacheco 1983:

9 Tomamos algunos ejemplos de la narrativa catalana del siglo XV como representantes tardíos de la literatura satírica medieval. Podemos encontrar el motivo fálico como objeto de deseo femenino independiente de un cuerpo masculino en otras tradiciones literarias, como es el caso de los fabliaux. Les IIII souhais Saint Martin (Montaiglon 1872-1890: V, 133) o De III dames que troverent un vit (Montaiglon 1872-1890: V, 32) podrían ser un buen ejemplo. La relación de esta tradición francesa con la narrativa catalana ha sido constante desde las observaciones de Amadeu Pagès. Si bien Pagès, en su estudio sobre «Le fabliau en Catalogne» (1929), sólo tuvo en cuenta la Disputació d'en Buch ab son cavall, los Planys del cavaller Mataró y El sagristà i la burgesa como auténticos fabliaux catalanes y no incluyó el Llibre de fra Bernat por considerarlo, junto al Testament de Bernat Serradell, más bien de influencia italiana (del Decamerón y del Corbaccio), la crítica posterior no ha dudado en emparentar la obra de De la Via de manera más o menos justificada con los fabliaux (desde Riquer (1984: II, 284) a Ysern (2006: 109)). Es evidente que, a nivel temático, el Llibre de fra Bernat conecta con los fabliaux de tono más procaz y con aquellos en los que la sexualidad ilícita (sobretodo, centrada en la actividad sexual de frailes y clérigos) aparece de manera más explícita y jocosa. A nivel formal, también es próximo a los fabliaux, pues está escrito en codolada, (octosílabos y tetrasílabos pareados), una variante formal de las noves rimades catalanas (octosílabos pareados), relacionada tradicionalmente con un contenido satírico, como es el caso. Pacheco (1983: 8) ya apuntó que ambas versificaciones «són un pont entre la literatura aristocràtica de les corts i les facècies $i$ contes tradicionals de les classes populars». Pero, si se acomete un análisis de la obra que tenga en cuenta los recursos narrativos y los mecanismos generadores de la parodia que De la Via utiliza, se podrá observar que éstos difieren en complejidad y agudeza de los utilizados por los autores de fabliaux, como observa Pacheco (1997: 46) y también — a su manera - Ottaiano (1993). Cingolani (1990), por su parte, ya apuntó que existían muy pocas obras francesas en las bibliotecas catalanas de los siglos XIV y XV, y sugirió que estos «contes plaents», como los llamó Riquer (1984: II, 256), tuvieran quizá sus fuentes y modelos en los exempla descontextualizadamente más divertidos y los novellini. Por otra parte, Jàfer (1988: 67) supo ver en el Col-loqui de dames y otras obras como Lo procés de les olives o El somni de Joan Joan la culminación cuatrocentista valenciana de toda la tradición satírica catalana precedente. 
289): «Lladoncs mès mans a la braga, / mostra-li son rave»; y en este momento añade el fraile: «Han tal bec vostres gallines?» ${ }^{10}$.

Ya es significativo, como veremos más adelante, que el autor designe el falo de este travieso fraile con la palabra «rave» ('rábano'), pero resulta aún más llamativo el hecho de que fray Bernat se dirija a la monjita refiriéndose a su órgano genital en unos términos que lo comparan con un «bec» ('pico') de ave, pues pregunta jocoso si las gallinas del convento tienen, en efecto, semejante pico. Aislados de cualquier interpretación cultural, estos versos no serían más que una manera regocijante de presentar la osadía sexual de un personaje dentro de lo que se puede considerar la sátira anticlerical de la literatura del XV. Sin embargo, si ponemos en relación estos versos con los ejemplos pictóricos de representación fálica que presentan el miembro viril con atributos de ave, las atrevidas palabras de fray Bernat se llenan de significado y podemos suponer en ellas las resonancias de una tradición que explicaría de dónde surje la ocurrencia del autor a la hora de presentar el falo erecto del sátiro fray Bernat como algo digno de compararse superlativamente al pico de una gallina.

\section{EL FALO Y SUS MIEDOS: EL DESAFÍO DEL CARAGOL}

No sólo existe en la Edad Media el pájaro-falo como representación animal fálica. Hacia finales del siglo XIII aparece en los márgenes de los manuscritos del norte de Francia, así como en algunos manuscritos flamencos e ingleses, la imagen del caracol, en salterios, libros de horas, breviarios, decretales, pontificales, un Lancelot du Lac, un Tristan, y un Recueil de poésies morales (Randall 1962: 358). Las modalidades de representación de esta imagen varían según el contexto, dado por el manuscrito en cuestión, pero parece que el modo de representación pictórica más recurrente presenta a un caballero, a pie o a caballo, enfrentándose cara a cara a un caracol, como si de un combate o una justa entre iguales se tratase (fig. 10, Livres dou tresor, de Brunetto Latini; y fig.11, Macclesfield Psalter, Morgan Library, New York).

El débil y miedoso caracol está asociado tradicionalmente con la cobardía en la mentalidad medieval de bestiario, así como el fiero y corajoso león está asociado con la valentía del guerrero. Por otra parte, la cobardía en la imagen del caracol aparece relacionada frecuentemente en la imaginería medieval con el pueblo de los lombardos. Lillian Randall (1962: 364) ya afirmaba que es así como aparece en 29 manuscritos datados entre 1290 y 1320, y que dicho significado se explica por la huída de los lombardos ante Carlomagno en 772 D.C., cuyo inesperado pánico sirvió a los hombres del medievo para glorificar la imagen heroica de Carlomagno a través de los siglos ${ }^{11}$.

10 «Entonces se metió mano a la braga/ [y] le mostró su rábano (...) «¿Tienen tal pico vuestras gallinas?». Ésta y las siguientes traducciones son mías.

11 En este episodio histórico el Papa Adriano II pidió ayuda a Carlomagno contra Desiderius, rey de los lombardos, que había invadido territorios pertenecientes al papado. Después de rechazar diversas propuestas de paz, Desiderio preparó sus hombres para el combate pero, ante la vista del ejército franco salió huyendo sin más, tal y como se narra en De gestis Carolini Magni, escrito por un monje de Saint Gall en la segunda mitad del siglo IX. El caso es que a raíz de este episodio, uno de los significados más recurrentes del caracol en los manuscritos góticos es el de la cobardía, normalmente asociada al pueblo lombardo (y toda la narrativa épica francesa contendrá esta idea), pueblo que además, junto a los judíos, era considerado en la Edad Media, por sus actividades de banca, casta de usureros. 


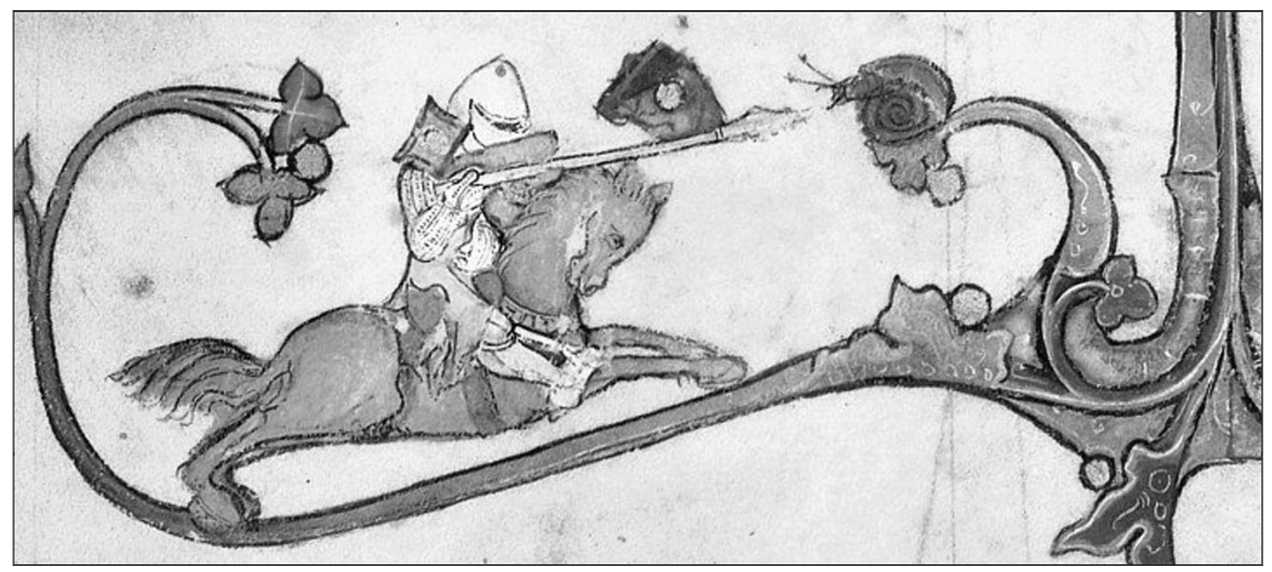

Fig. 10.

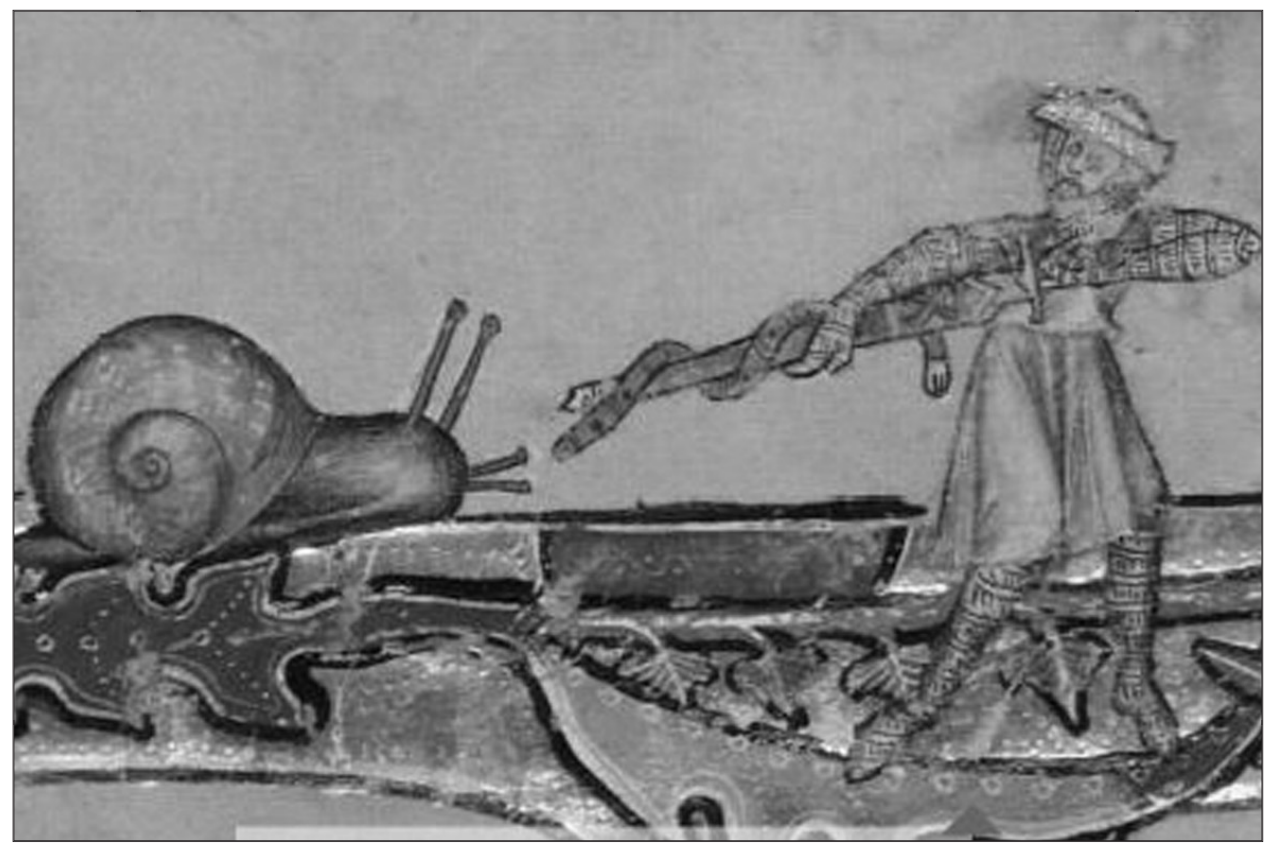

Fig. 11. 


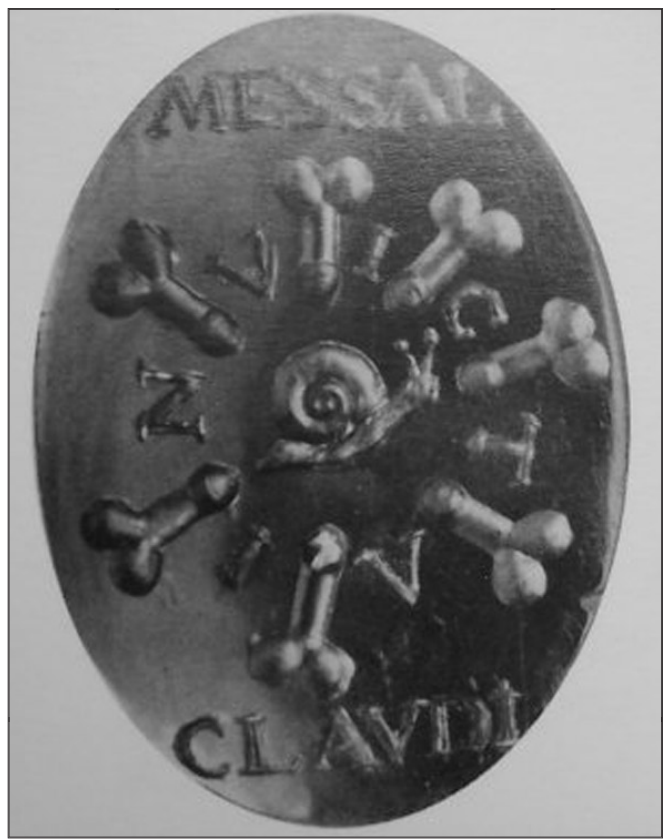

Fig. 12.

Por su forma y sus características fisiológicas, el caracol también estuvo relacionado en la mente medieval con los genitales femeninos. En este caso, parece tratarse de un significado pictórico que existía ya en la cultura romana. Al menos, así lo podemos interpretar a la vista de una gema antigua conservada, grabada en hueco, que muestra un caracol rodeado de falos amenazantes con la inscripción «MESSAL[INA] INVICTA CLAUDI[VS]» (fig. 12), haciendo clara alusión al temperamento fogoso de la mujer del emperador Claudio (Engammare 2008: 137). Desde otro punto de vista radicalmente distinto, el caracol incluso ha sido considerado símbolo de la resurrección de Cristo (Camille 1992: 31). Pero existe una interpretación que es la que nos interesa, pues nos da la clave de lectura adecuada para acercarnos a algunos de los textos satíricos más importantes de la Valencia del siglo XV: el caracol en los manuscritos medievales, por su lentitud e incapacidad de movimientos, también es símbolo de la impotencia sexual masculina.

Desde este punto de vista, tiene cierto sentido que sea representado ante un caballero que intenta combatirlo a toda costa, normalmente con una larga lanza o una espada, puesto que la impotentia convierte al caballero en desarmado cobarde en la batalla del amor ${ }^{12}$.

12 El encuentro amoroso conceptuado a modo de batalla no es algo nuevo, podemos observarlo en diferentes textos medievales y es de sobra conocido que Joanot Martorell, por ejemplo, disfrutaba utilizando léxico caballeresco y militar en las escenas amorosas que aparecen en su Tirant lo Blanc. Valga el ejemplo representativo de la «batalla delitosa» del capítulo 436, cuando Tirant entra, por fin, en el castell de Carmesina. 


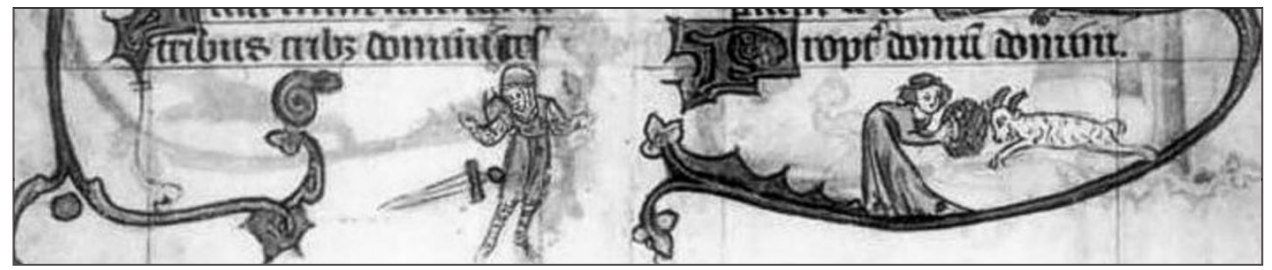

Fig. 13.

Es lo que encontramos en una escena miniada en un salterio flamenco conservado en la Kongelige Bibliotek de Copenhagen, donde un caballero deja caer su espada ante un caracol y donde, además, una dama amortigua el metafórico embiste de un macho cabrío con una cesta (fig. 13) ) $^{13}$.

Cuando relacionamos comparativamente estas drôleries con obras como Lo procés de les olives, de Bernat Fenollar, o Lo somni de Joan Joan, del caballero Jaume Gassull (ambas publicadas en Valencia en 1497), surgen como resultado las claves de lectura pertinentes que ayudan a interpretar algunas peculiares metáforas sexuales que aparecen en estos textos ${ }^{14}$. Ambas obras versan, con buena dosis de ironía retórica y mordacidad burlesca, sobre las capacidades amatorias de viejos y jóvenes (la primera, a modo de debate entre Fenollar, el notario Joan Moreno y Gassull; la segunda, algo más narrativa, pero también una disputatio entre mujeres y viejos, escrita por este último para dar su propia sentencia sobre el tema). Así, en Lo procés podemos encontrar veinticuatro alusiones a un caragol que, si pertenece a los viejos (representados por mossèn Fenollar), es «chich» ('pequeño'), «mustiu» ('mustio'), «fluix» ('flojo'), «reclam (...) de guatles» ('reclamo de codornices', es decir, esmirriado como un gusano), «fret» ('frío'), «vell» ('viejo'), «mort», imposible de «alçar», «flach»y «trist». Si, por el contrario, es un caragol de jóvenes (representados por Moreno), se presenta como «bell», «viu», «dur»y «dolç»15. El caracol implica, en este caso, una ambivalente metáfora fálica que hace referencia bien a la flác-

13 El problema físico de la impotentia fue, sobretodo a partir del siglo XII, objeto de densas elucubraciones por parte de teólogos y especialistas en el derecho canónico. La frigidez y la impotencia constituían causas de anulamiento del matrimonio, ya que el contrato matrimonial implicaba un debitum, el débito conyugal, que los individuos afectados por estas dolencias no podían pagar oportunamente. Aunque en la práctica social los matrimonios con hombres de cierta edad fueran cada vez más frecuentes y, en consecuencia, se llegara a clasificar esta dolencia como impotentia respectiva, naturalis, accidentalis, certa o dubia, etc., en la literatura médica se puede apreciar la preocupación por descubrir los signos e indicios físicos que pudieran implicar el problema sexual del defectus coitus. Arnau de Vilanova, Bernardo de Gordonio, Gaddesden y otras auctoritates médicas, se basaban en el Canon de Avicena y en el Pantegni de Constantinus Africanus como fuentes sobre este tema (Jacquart 1988: 169-173).

14 La tesis enunciada por Randall (1962: 359) sobre este motivo pictórico coincide con el hecho de encontrarnos el símbolo sexual o fálico del caracol en la literatura del XV: «Like many other subjects popularized in marginal illumination of about 1300, the snail combat gradually disappeared in the course of the fourteenth century, to be revived once more with special applicability to contemporary events at the end of the fifteenth century».

15 Versos 7, 15, 31, 39, 47, 55, 63, 79, 95, 103, 119, 127, 135 y 143 de la edición de Llúcia Martín et alii (2005). Cf. bibliografía final. 
cida impotencia amorosa de los viejos, bien a la vivacidad sexual de los jóvenes (que son una impotencia y una vivacidad metafóricamente fálicas).

En Lo somni de Joan Joan, por otra parte, existen cuatro referencias al caragol de los viejos. La primera se encuentra en la «denunciació» contra los viejos que hacen las mujeres reunidas en la obra, afirmando que «si per desastre alça el cap/ son caragol,/ tantost està fet un bunyol»; y eso es así «perquè en guaret sec/ tostemps se peixen» ${ }^{16}$ (Pacheco 1983: 328-329). El notario Joan Moreno aparecerá en esta obra como abogado defensor de los viejos ante la diosa Venus, a quien afirmará, contestando a lo dicho por las mujeres que «trobant bona pastural son caragol,/ ab tot que sia molt bunyol,/ traurà la banya ${ }^{17}$ (Pacheco 1983: 332). La tercera referencia aparece en una «escriptura posada per part dels vells» defendiendo su derecho a los quehaceres amorosos de esta guisa: lo caragoll del vell, tenint plec de bunyol,/ per ço no restal no sia gall, puix que té crestal tan bé vermella ${ }^{18}$ (Pacheco 1983: 338).

Sin embargo, la sentencia final emitida por la diosa Venus, juez de excepción en este particular debate, constituirá la cuarta referencia al caracol de los viejos y será definitiva en cuanto a su condena como participantes en la batalla del amor «vist que entra tostemps doblegat/ son caragol,/ i és ja provat ésser bunyol,/ segons lo plec» ${ }^{19}$ (Pacheco 1983: $366)^{20}$.

\section{FRUTOS SABROSOS Y OTRAS METÁFORAS GROTESCAS}

Como hemos visto, en cuanto a la representación medieval del falo, resulta pertinente recurrir a lo que podemos encontrar en los márgenes de los manuscritos bajomedievales, concretamente, en aquellos que presentan atrevidas y divertidas drôleries ${ }^{21}$. En este senti-

16 «Si por desastre levanta la cabeza/ su caracol,/ pronto está hecho un buñuelo (...) porque en barbecho seco/ siempre pasturan».

17 Que «encontrando buena pastura/ su caracol [el de los viejos]/ aunque sea muy buñuelo/ sacará el cuerno».

18 «El caracol/ del viejo, aun teniendo pliegue de buñuelo,/ no quiere decir/ que no sea gallo, pues tiene cresta/ también roja».

19 «Visto que entra siempre doblado/ su caracol,/ y está ya probado que es buñuelo/ según su pliegue».

20 Como contrapunto a lo que representa el caracol en estos textos, podemos encontrar en los mismos la imagen del hurón como representación animal metafórica de una sexualidad fálica activa, siempre con ganas de «escorcollar» rincones y madrigueras, y de cazar tiernas «llebres» (o, al menos, en teoría). Así aparece en el Col-loqui de dames (v. 417), en Lo procés de les olives (vv. 611, 694) y en Lo somni de Joan Joan (Pacheco 1983: 305, 325).

21 Podemos situar la génesis iconográfica de estas drôleries hacia la mitad del siglo XIII, apareciendo con ciertas preferencias temáticas: la caza, el juego, la música, etc., y con una clara desnaturalización de las figuras que aparecen en ellas (híbridos, animales imitando a los hombres, personajes con comportamientos aberrantes, etc.). La mayoría de los motivos iconográficos que componen estas gracias o bufonerías pictóricas aparecen ya en el arte románico. Sin embargo, muchos otros son exclusivos de los manuscritos góticos y tienen un origen cultural y un propósito diferentes. Los temas profanos, bizarros, licenciosos, con monstruos, grotescos y figuras obscenas se mantienen en el arte de la marginalia tardomedieval. Pero mientras que en el arte decorativo románico, con la reforma gregoriana, la interpretación de estos temas iconográficos se adaptará a una mentalidad y a un programa religioso que pretende aplicar la imaginería de los templos a un didactismo basado en el temor de los pecados (y, sobretodo, los pecados de la carne), las drôleries manuscritas se alejaran en cierta medida de esta concepción y presentarán significados diversos relacionados con las ideas sobre la sexualidad medieval o la sátira anticlerical (Engammare 2008: 79). 


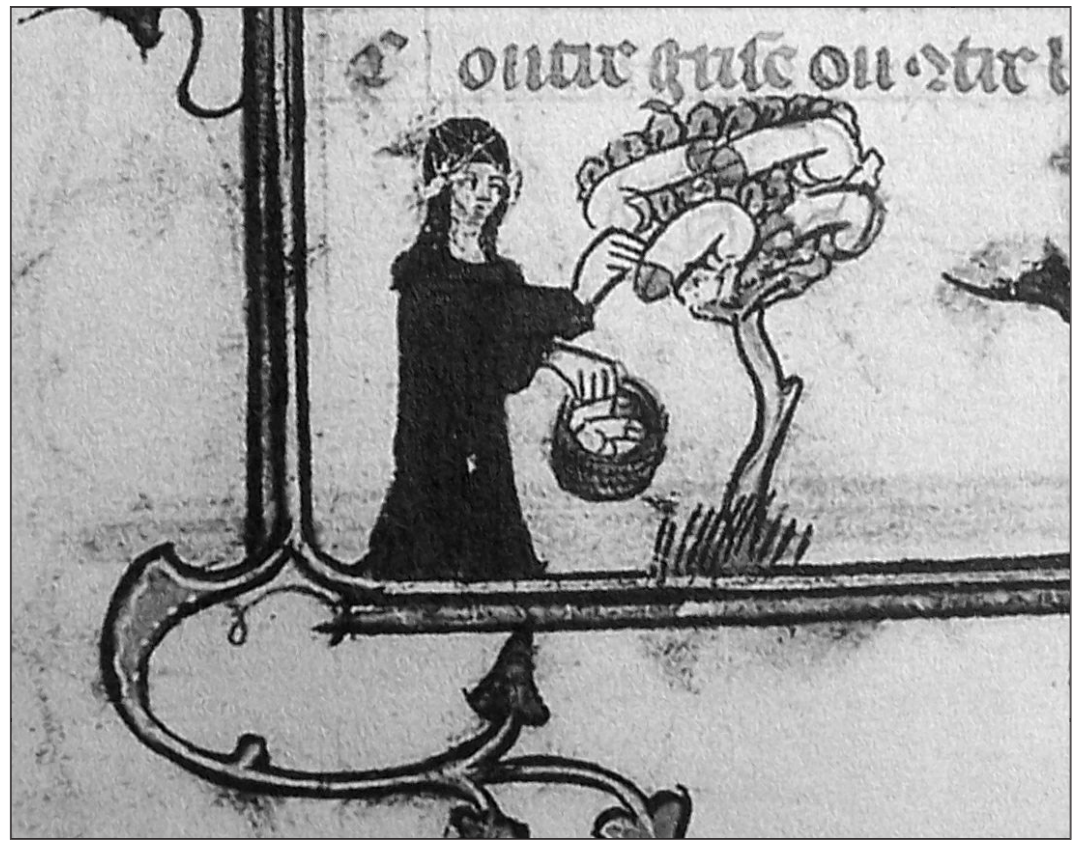

Fig. 14.

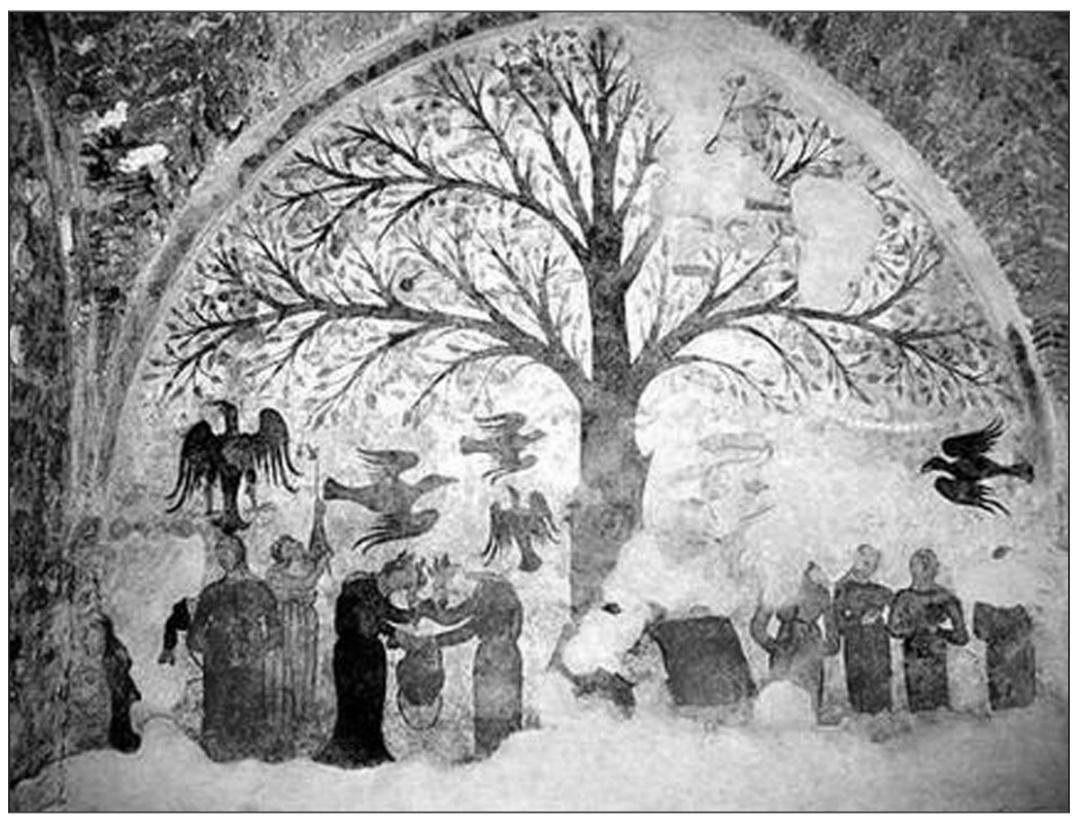

Fig. 15. 


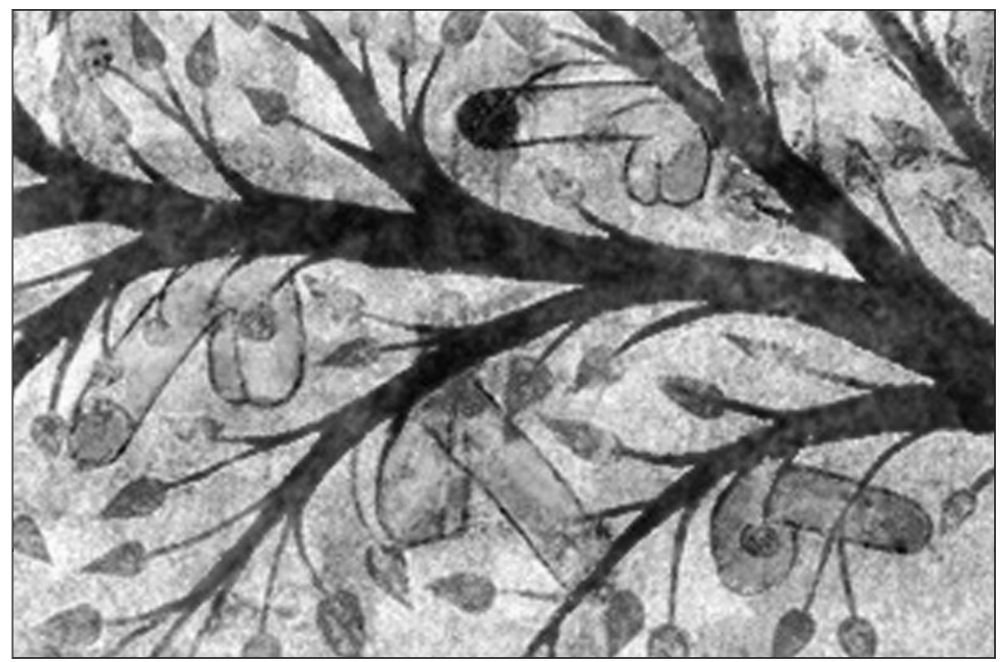

Fig. 16.

do, si adoptamos como marco cultural la crítica anticlerical que empieza hacia la mitad del siglo XIII (centrada, sobretodo, en el nicolaísmo y simonía de las órdenes mendicantes) y que ya a mediados del XIV se había convertido en algo más bien convencional y mecánico (Elsig 2008: 276, 287), podemos encontrar alguna drolería que sirve para ejemplificar una tipología de representación fálica diferente. Es el caso de una miniatura que encontramos en el Roman de la Rose (fr. 25526) iluminado en París en el taller de Richard y Jeanne Montbaston (1350), formando parte del repertorio anticlerical de la marginalia gótica (que ridiculizaba prácticamente toda la jerarquía eclesiástica). Al pie del folio 106v. podemos apreciar una monja clarisa que podría considerarse digna heredera del pecado original, pues se encuentra recolectando ávidamente unos particulares frutos en forma de falo que cuelgan de un árbol (fig. 14), lo que recuerda al tópico sobre la lascivia de las monjas y los quehaceres amorosos de las jóvenes malmonjadas que ingresaban en el convento en contra de su voluntad, como es el caso de la monjita que aparece en el Llibre de fra Bernat $^{22}$, donde además encontramos el falo erecto del protagonista designado mediante el término «rave».

Existe otro ejemplo pictórico medieval que presenta el falo como fruto deseado por la mujer en el mural del siglo XIII descubierto en el año 2000 en la población toscana de Massa Maritima, donde podemos contemplar un gran árbol cargado de falos, bajo el

22 De hecho, en el folio 111 del mismo manuscrito de este Roman de la Rose encontramos el coito explícito entre un laico y la monja en cuestión. Viene también al caso una composición de Diego Sánchez de Badajoz (Frenk 2003: 284): No me las enseñes más, / que me matarás. / Estábase la monjal en el monesterio,/ sus teticas blancas/ de so el velo negro./ Más,/ que me matarás. 


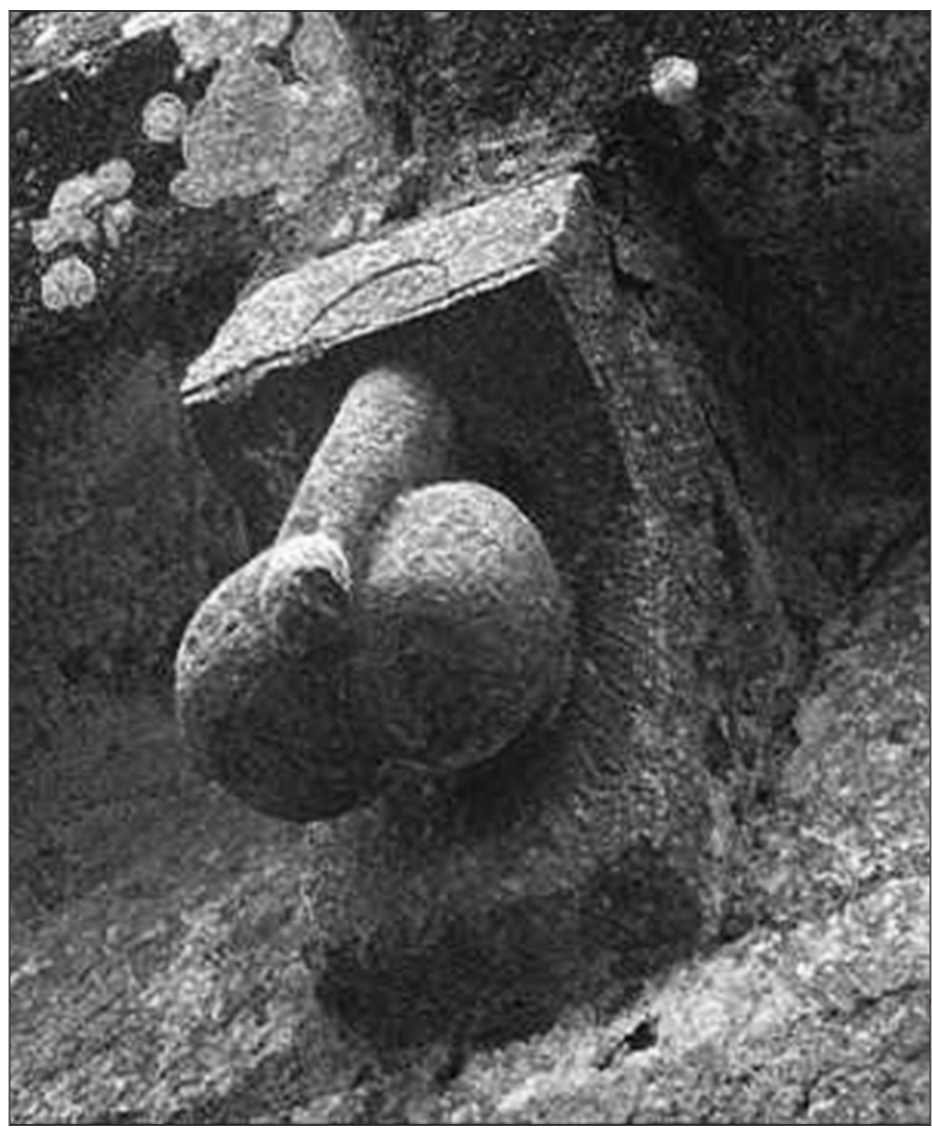

Fig. 17.

que diversas mujeres se disputan la cosecha (figs. 15 y 16) ${ }^{23}$. Anterior en el tiempo es el modillón románico de la iglesia de Sainte Colombe, en Charente (Francia), conformado por un falo y dos considerables testículos que cuelgan hacia abajo como si de dos enormes frutos se tratasen (fig. 17). Este modo de representación pictórica del falo tiene que ver

23 El mural muestra un árbol de gran ramaje bajo el cual aparecen unas águilas sobrevolando cuatro mujeres a la izquierda del tronco y otras cuatro a la derecha. De las cuatro mujeres de la izquierda, parece que dos quieran apoderarse de un nido de águila (o del ave que sea) o bien conseguir uno de los falos botánicos. Las otros dos se pelean estirándose de los cabellos por uno de estos apreciados frutos. Por todo ello, podría pensarse que nos encontramos ante la imagen más antigua de la representación de brujas en la Europa cristiana medieval. Y es que en un pasaje del Malleus maleficarum (1486, aunque yo he consultado la edición de 1580 de la Cornell University Library) podemos leer que las brujas robaban los genitales a los hombres mediante un encantamiento y los colocaban en cenachos y en nidos en los árboles, donde se multiplicaban y se alimentaban de avena y trigo, como si de alegres pajarillos se tratase (parte segunda, quaestio 1, cap. VII), lo que recuerda a los olisboi paganos y los pájaros-falo de la cerámica ática. 
con las ideas medievales sobre el deseo sexual femenino, considerado insaciable, y que se basaban en la teoría galénica de los cuatro humores para pensar a la mujer como un ser exacerbadamente lujurioso, con exceso de humedad y de frío y, por ello, siempre en busca del calor del lecho ${ }^{24}$. Es lo que podemos encontrar, desde un punto de vista satírico, en el anónimo Col-loqui de dames (en el manuscrito Jardinet de orats, 1486), en el que tres adúlteras y lascivas mujeres (una Casada, una Viuda y una Beata) utilizan grotescas y violentas metáforas fálicas para referirse al miembro viril de sus amantes - casi todos eclesiásticos - y donde, en este sentido, aparecen los términos «punyal» y «matràs» 25 . Este matraz, además, también aparece «ben format» y «drets» en el Llibre de fra Bernat para designar el «rave» del fraile protagonista; e incluso Gassull empleará el vocablo en Lo somni de Joan Joan (Pacheco 1983: 289 y 332, respectivamente).

\section{CONCLUSIONES}

Estas notas han pretendido simplemente un ensayo de inventario interpretativo a través de algunos ejemplos que resultan paradigmáticos para comprender la representación cultural del elemento fálico a lo largo de la Edad Media. No podemos negar, en este sentido, la evidencia de una herencia cultural proveniente del mundo clásico: una herencia pictórica que se ve modificada, a la que se añaden las respectivas ideas medievales sobre la sexualidad, tanto masculina como femenina (algunas de las cuales también proceden de autores clásicos). Los miedos morbosos del falogocentrismo medieval, centrados en la impotencia del hombre y el deseo insaciable femenino se sitúan en el transfondo de imágenes que proceden de la Antigüedad tardía y que perviven, pasando por el arte románico y la marginalia manuscrita, hasta llegar a textos literarios del siglo XV. Un recorrido por estas ideas, imágenes y metáforas puede proporcionarnos las claves necesarias para una mayor comprensión de la sexualidad en la cultura del medievo, obteniendo así algunos datos interesantes para el estudio de la mentalité, el arte y la literatura medieval.

\section{BIBLIOGRAFÍA}

BOYMEL, Natalie, ed. (1996) Sexuality in Ancient Art, Cambridge, Cambridge University Press.

CABANES, Pilar (2003) «La sexualidad en la Europa medieval cristiana», Lemir: Revista de Literatura Española Medieval y del Renacimiento 7 (http://parnaseo.uv.es/Lemir/ Revista/Revista7/Revista7.htm).

- (2005) «El deseo femenino a la luz de algunas composiciones literarias medievales», Lemir: Revista de Literatura Española Medieval y del Renacimiento 9 (http: //parnaseo.uv.es/Lemir/Revista/Revista9/Revista9.htm).

24 «El aristotelismo reinante le había hecho creer [al hombre medieval] que el exceso de humedad en su cuerpo le daba una capacidad erótica ilimitada, que difícilmente se podía saciar. Y la fórmula de Juvenal, lassata uiris necdum satiata -cansada de hombres pero no satisfecha- era susurrada una y otra vez por los fantasmas masculinos» (Cabanes 2003: 6). Cf. también Cabanes (2005).

25 Versos 317, 549 y 720 (Martín: 2006). 
CAMILLE, Michael (1992) Image on The Edge. The Margins of Medieval Art, London, Reaktion Books.

CINGOLANI, Stefano (1990) «'Nos en leyr tales libros trobemos plazer e recreation': L'estudi sobre la difusió de la literatura d'entreteniment a Catalunya en els segles XIV i XV», Llengua i Literatura 4, pp. 39-127.

ELSIG, Frederic (2008) «La ridiculisation du système religieux», in Jean Wirth, ed., Les marges à drôleries des manuscrits gothiques, Genève, Librairie Droz, pp. 276-306.

ENGAMMARE, Isabelle (2008) «L'influence des collections d'antiques», in Jean Wirth, ed., Les marges à drôleries des manuscrits gothiques, Genève, Librairie Droz, pp. 129-143.

FRENK, Margit (2003) Nuevo corpus de la antigua lírica popular hispánica, siglos XV a XVII, vol.I, México, Fondo de Cultura Económica.

FRONTISI-DUCROUX, Françoise (1996) «Eros, desire, and the gaze», in Natalie Boymel, ed., Sexuality in Ancient Art, Cambridge, Cambridge University Press, pp. 81100.

GRANT, Michael (1975) Eros in Pompeii: the secret rooms of the National Museum of Naples, New York, Morrow.

HALPERIN, David et alii, eds. (1990) Before Sexuality: The Construction of Erotic Experience in The Ancient Greek World, Princeton, Princeton University Press.

JACQUART, Danielle et THOMASSET, Claude (1988) Sexuality and Medicine in The Middle Ages, Cambridge, Polity Press.

JÀFER, Salvador (1988) «Introducció» a Vicent Pitarch, ed., Lo procés de les olives, València, Tres i Quatre.

JOHNS, Catherine (2004) Little Book of Erotica, London, The British Museum Press.

KEULS, Eva C. (1993) The Reign of the Phallus: Sexual Politics in Ancient Athens, California, University of California Press.

KRAMER, Heinrich et SPRENGER, Jacob (1580) Malleus maleficarum, Frankfurt am Main, Nicolaum Bassaerum (ed. facsímil de la Cornell University Library).

LISSARRRAGUE, François (1990) «The Sexual Life of Satyrs», in David Halperin et alii, eds, Before Sexuality: The Construction of Erotic Experience in The Ancient Greek World, Princeton, Princeton University Press, pp. 53-82.

MARTÍN, Llúcia et alii., eds. (2005) Lo procés de les olives, Biblioteca Virtual Joan Lluís Vives (http://www.cervantesvirtual.com/FichaObra.html?Ref=14294\&portal=0).

MARTÍN, Llúcia, ed. (2006) Col-loqui de dames, Biblioteca Virtual Joan Lluís Vives (http://www.cervantesvirtual.com/FichaObra.html?Ref=20155\&portal=0).

MONTAIGLON, Anatole de et RAYNAUD, Gaston (1872-1890) Recueil général et complet des fabliaux des XIIIe et XIVe siècles, 6 vols., Paris, Libraire des bibliophiles.

OTTAIANO, Antonio (1993) «Els fabliaux catalans: Anàlisi d'una definició», in Antoni Ferrando, ed., Miscel-lània Joan Fuster, Barcelona, Publicacions de l'Abadia de Montserrat, pp. 5-43.

PACHECO, Arseni, de. (1983) Blandín de Cornualla $i$ altres narracions en vers dels segles XIV-XV, Barcelona, Edicions 62.

- (1997) Francesc de la Via. Obres, Barcelona, Quaderns Crema. 
PAGÈS, Amadeu (1929) «Le fabliau en Catalogne», Estudis Universitaris Catalans 14, pp. 311-22.

RANDALL, Lillian (1962) «The Snail in The Gothic Marginal Warfare», Speculum 37, $\mathrm{n}^{\mathrm{o}} 3$, pp. 358-67.

RIQUER, Martí de (1984) Història de la literatura catalana, vol. II, Barcelona, Ariel.

SKINNER, Marilyn B. (2005) Sexuality in Greek and Roman Culture, Oxford, Blackwe11.

TANNAHILL, Reay (1991) Sex in History, London, Cardinal.

WIRTH, Jean, ed. (2008) Les marges à drôleries des manuscrits gothiques, Genève, Librairie Droz.

YSERN, Josep-Antoni (2006) «A propòsit del Llibre de fra Bernat», Revista de Lenguas y Literaturas Catalana, Gallega y Vasca 12, pp. 85-113. 